\title{
PENGARUH KETEBALAN DINDING DAN TEKANAN INTERNAL TERHADAP FAKTOR KEAMANAN TABUNG MOTOR ROKET DEXTROSE MENGGUNAKAN ANSYS WORKBENCH
}

\author{
Lasinta Ari Nendra Wibawa \\ Lembaga Penerbangan dan Antariksa Nasional (LAPAN) \\ Email: lasinta.ari@lapan.go.id \\ Unggul Satrio Yudhotomo \\ Lembaga Penerbangan dan Antariksa Nasional (LAPAN) \\ Email: unggul.satrio@lapan.go.id \\ Yudi Haryanto \\ Lembaga Penerbangan dan Antariksa Nasional (LAPAN) \\ Email: yudi.haryanto@lapan.go.id \\ Arief Kurniawan \\ Lembaga Penerbangan dan Antariksa Nasional (LAPAN) \\ Email: arief.kurniawan@lapan.go.id
}

\begin{abstract}
ABSTRAK
Salah satu komponen penting pada roket Dextrose adalah tabung motor roket. Penelitian ini bertujuan untuk merancang tabung motor roket Dextrose yang mampu menahan tekanan internal $5 \mathrm{MPa}$. Pada penelitian ini, desain tabung roket Dextrose menggunakan silinder berdinding tebal dengan diameter luar 32 $\mathrm{mm}$, radius fillet $2 \mathrm{~mm}$, dan panjang $200 \mathrm{~mm}$. Variasi ketebalan dinding yang digunakan yaitu $2 \mathrm{~mm}, 2.5$ $\mathrm{mm}$, dan $3 \mathrm{~mm}$. Tekanan internal divariasikan mulai dari 1, 2, 3, 4, dan $5 \mathrm{MPa}$. Material yang digunakan dalam penelitian yaitu Aluminium 6063-T5. Analisis tegangan statik dilakukan dengan bantuan perangkat lunak Ansys Workbench. Hasil simulasi Ansys menunjukkan bahwa tabung motor roket dengan ketebalan $3 \mathrm{~mm}$ mampu menahan tekanan internal hingga $5 \mathrm{MPa}$ karena memiliki faktor keamanan lebih dari 2, yaitu 2.58. Perbandingan nilai tegangan Longitudinal dan Hoop maksimum antara simulasi Ansys Workbench dan perhitungan analitik digunakan untuk validasi hasil penelitian. Persentase kesalahan antara simulasi Ansys Workbench dan perhitungan analitik kurang dari 0.5 persen.
\end{abstract}

Kata kunci: ansys workbench, ketebalan dinding, roket dextrose, tabung motor roket, tekanan internal

\section{ABSTRACT}

One of the important components in the Dextrose rocket is the rocket motor tube. This study aims to design a Dextrose rocket motor tube that can withstand an internal pressure of $5 \mathrm{MPa}$. In this study, the design of the Dextrose rocket tube used a thick-walled cylinder with an outer diameter of $32 \mathrm{~mm}$, a fillet radius of $2 \mathrm{~mm}$, and a length of $200 \mathrm{~mm}$. The variations in wall thickness used were $2 \mathrm{~mm}, 2.5 \mathrm{~mm}$, and $3 \mathrm{~mm}$. Internal pressure varies from 1, 2, 3, 4, and $5 \mathrm{MPa}$. The material used in this research is Aluminum 6063-T5. Static stress analysis was carried out with the help of Ansys Workbench software. Ansys simulation results show that the rocket motor tube with a thickness of $3 \mathrm{~mm}$ can withstand internal pressures of up to $5 \mathrm{MPa}$ because it has a safety factor of more than 2, namely 2.58. The comparison of the maximum longitudinal and hoop stress values between the Ansys Workbench simulation and analytical calculations was used to validate the research results. The percentage of error between Ansys Workbench simulation and analytical calculations is less than 0.5 percent.

Keywords: ansys workbench, wall thickness, dextrose rocket, rocket motor case, internal pressure 


\section{PENDAHULUAN}

Roket Dextrose merupakan roket yang menggunakan bahan bakar Kalium Nitrat atau Potassium Nitrat $\left(\mathrm{KNO}_{3}\right) /$ Dextrose. Kalium nitrat yang juga merupakan bahan dasar pupuk tersebut berfungsi sebagai oksidator, sedangkan Dextrose berfungsi sebagai binder bahan bakar (fuel binder). Pada umumnya, persentase perbandingannya yaitu 65 persen Kalium Nitrat dan 35 persen Dextrose. Bahan bakar roket dari Kalium Nitrat/Dextrose (KNDX) ini cukup populer dan banyak digunakan untuk penelitian roket mahasiswa di beberapa kampus di luar negeri, selain Kalium Nitrat/Sorbitol (KNSB) dan Kalium Nitrat/Sucrose (KNSU) [1]-[6].

Roket Dextrose dapat menjadi bahan edukasi tentang teknologi peroketan yang relatif murah selain roket air (water rocket). Salah satu kelebihan roket Dextrose adalah jarak jangkau yang lebih jauh daripada roket air. Tingkat risiko ledakan roket Dextrose juga tergolong rendah dibandingkan dengan menggunakan propelan dari bahan Hydroxyl-terminated polybutadiene (HTPB).

Salah satu komponen penting pada roket Dextrose adalah tabung motor roket. Tabung motor roket berperan penting karena berisi bahan bakar. Desain dan pengaturan parameter tabung sangat penting agar tabung roket dapat menahan beban kerja yang berasal dari tekanan internal dan temperatur ruang bahan bakar (combustion chamber).

Tekanan internal dan ketebalan dinding merupakan faktor yang berpengaruh terhadap tegangan von Mises maksimum pada silinder yang menggunakan prinsip bejana tekan [7]-[9]. Selain tekanan internal dan ketebalan dinding, faktor lain seperti ketebalan cap roket dan radius fillet juga berpengaruh terhadap tegangan von Mises maksimum [9]-[11]. Pada penelitian ini, nilai radius fillet, ketebalan cap, dan panjang tabung roket Dextrose konstan.

Desain tabung roket Dextrose menggunakan silinder berdinding tebal dengan diameter luar $32 \mathrm{~mm}$ atau sekitar $5 / 4$ inchi, radius fillet $2 \mathrm{~mm}$, dan panjang $200 \mathrm{~mm}$. Variasi ketebalan dinding yang digunakan yaitu 2 , 2.5, dan $3 \mathrm{~mm}$. Tekanan internal divariasikan mulai dari 1,2, 3, 4, dan $5 \mathrm{MPa}$. Material yang digunakan dalam penelitian yaitu Aluminium 6063-T5 yang merupakan material dengan massa jenis ringan, kekuatan medium, harga relatif murah, dan mudah ditemukan di pasaran.

Analisis tegangan statik menggunakan perangkat lunak Ansys Workbench dengan metode elemen hingga. Ansys adalah salah satu perangkat lunak yang paling sering digunakan untuk simulasi tabung motor roket. Ansys memiliki kelebihan karena dapat diintegrasikan dengan hampir semua perangkat lunak jenis Computer-Aided Design (CAD) antara lain Autodesk Inventor, SolidWorks, Catia, dan Creo.

\section{METODE PENELITIAN}

Bejana tekan berdasarkan dimensinya dibagi menjadi dua, yaitu berdinding tipis dan berdinding tebal. Bejana tekan yang memiliki ketebalan dinding lebih kecil dari $1 / 20$ diameter internalnya disebut berdinding tipis. Bejana tekan yang memiliki ketebalan dinding lebih besar dari 1/20 diameter internalnya disebut bejana tekan berdinding tebal.

Pada penelitian ini, ketebalan dinding $2 \mathrm{~mm}, 2.5 \mathrm{~mm}$, dan $3 \mathrm{~mm}$ sehingga dapat diklasifikasikan sebagai bejana tekan berdinding tebal karena semua nilai tersebut lebih besar dari $1 / 20$ diameter internalnya, tepatnya $1 / 20 \times 26 \mathrm{~mm}=1.3 \mathrm{~mm}$.

Pada kasus silinder berdinding tebal, tekanan yang bekerja pada bagian dinding silinder tidak bisa dianggap terdistribusi merata seperti pada kasus silinder berdinding tipis [12]. Besar kecilnya tegangan radial dan hoop dipengaruhi oleh jari-jari silinder.

Teori Elastisitas merupakan teori pokok untuk silinder berdinding tebal yang menghasilkan kondisi tegangan sebagai fungsi kontinyu dari jari-jari di atas dinding silinder [13]. Tegangan dalam silinder tergantung pada rasio antara jari-jari dalam ke jari-jari luar $\left(\mathrm{r}_{\mathrm{o}} / \mathrm{r}_{\mathrm{i}}\right)$ dibandingkan dengan ukuran silinder.

Tegangan yang terjadi pada silinder berdinding tebal terjadi pada 3 arah, yaitu hoop atau circumferential, axial atau longitudinal, dan radial.

$$
\left(\sigma_{h}\right)_{\max }=p_{i}\left(\frac{r_{o}^{2}+r_{i}^{2}}{r_{o}^{2}-r_{i}^{2}}\right)
$$




$$
\begin{aligned}
& \left(\sigma_{l}\right)_{\max }=p_{i}\left(\frac{r_{i}^{2}}{r_{o}^{2}-r_{i}^{2}}\right) \\
& \left(\sigma_{r}\right)_{\max }=-p_{i}
\end{aligned}
$$

Di mana $\mathrm{p}_{\mathrm{i}}=$ tekanan internal $(\mathrm{MPa}), \mathrm{r}_{\mathrm{i}}=$ jari-jari dalam silinder $(\mathrm{mm})$, dan $\mathrm{r}_{\mathrm{o}}=$ jari-jari luar silinder ( $\mathrm{mm})$.

Faktor keamanan pada kasus ini menggunakan kekuatan tarik maksimum karena tabung roket Dextrose merupakan komponen habis pakai [10].

$$
F O S=\frac{U T S}{\sigma v M_{\max }}
$$

Di mana FoS = faktor keamanan, UTS= tegangan tarik maksimum $(\mathrm{MPa})$, dan $\sigma \mathrm{vM}_{\max }=$ tegangan von mises maksimum (MPa).

Gambar 1 menunjukkan dimensi tabung roket Dextrose. Karena sifat silinder yang simetri pada arah longitudinal, maka pemodelan silinder dapat dilakukan dengan setengah bagian atasnya [14]. Penelitian ini cukup menggunakan model seperdelapan bagian silinder. Hal ini sesuai dengan Hukum Pascal yang menyatakan bahwa tekanan yang diberikan pada fluida dalam ruang tertutup maka tekanan tersebut akan diteruskan merata ke segala arah dan sama besar [15].

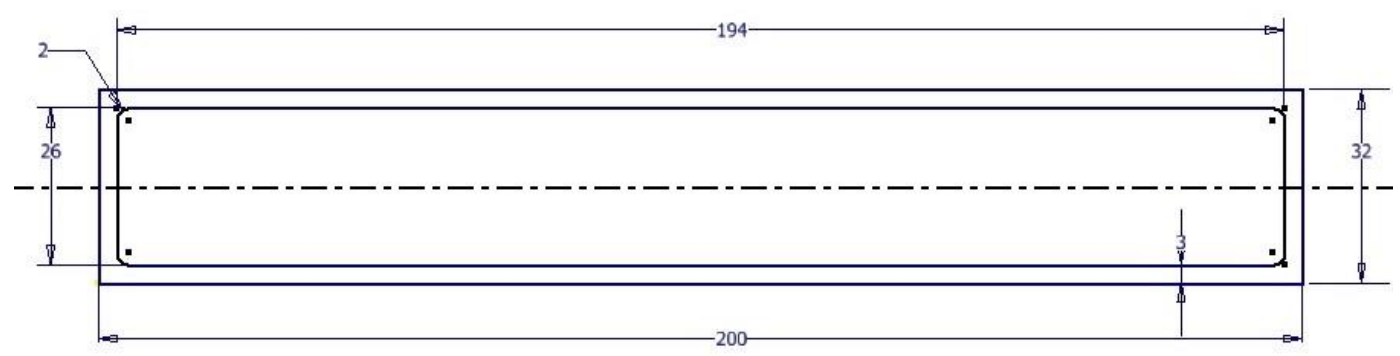

Gambar 1. Desain tabung roket Dextrose dengan diameter luar $32 \mathrm{~mm}$, radius fillet $2 \mathrm{~mm}$, ketebalan dinding $3 \mathrm{~mm}$, dan panjang $200 \mathrm{~mm}$.

Gambar 2 menunjukkan kondisi batas frictionless support dan pembebanan. Frictionless support berarti node dibatasi dalam arah radial (mirip dengan cylindrical support di bidang mekanik, dengan arah radial tetap, tetapi arah aksial dan tangensial bebas). Parameter simulasi menggunakan Ansys Workbench ditunjukkan pada Tabel 1. Ukuran elemen untuk semua variasi diatur seragam, yaitu $1.2 \mathrm{~mm}$. Hal ini tentu berdampak pada jumlah elemen dan node untuk tiap variasi penelitian ada sedikit perbedaan, tetapi tidak signifikan.
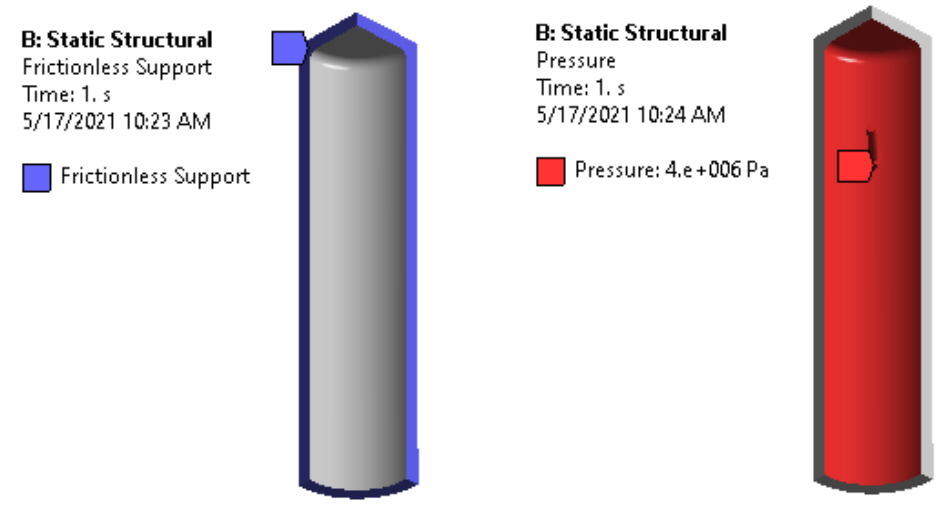

Gambar 2. Kondisi batas Ansys berupa frictionless support (kiri) dan pembebanan (kanan) 
Tabel 1. Parameter simulasi menggunakan Ansys Workbench.

\begin{tabular}{cc}
\hline Parameter & Keterangan \\
\hline Panjang tabung & $200 \mathrm{~mm}$ \\
Diameter luar & $32 \mathrm{~mm}$ \\
Radius fillet & $2 \mathrm{~mm}$ \\
Ketebalan dinding & $2 \mathrm{~mm}, 2.5 \mathrm{~mm}$, dan $3 \mathrm{~mm}$ \\
Tekanan internal & $1,2,3,4$, dan $5 \mathrm{MPa}$ \\
Ukuran elemen & $1.2 \mathrm{~mm}$ \\
Jumlah node & $25534(2 \mathrm{~mm}), 25621(2.5 \mathrm{~mm}), 24888(3 \mathrm{~mm})$ \\
Jumlah elemen & $13916(2 \mathrm{~mm}), 13902(2.5 \mathrm{~mm}), 13811(3 \mathrm{~mm})$ \\
\hline
\end{tabular}

Persyaratan utama untuk material tabung motor roket Dextrose adalah massa jenis ringan, relatif murah, dan memiliki kekuatan medium. Aluminium 6063-T5 dipilih karena memenuhi persyaratan tersebut. Al 6063-T5 memiliki sifat mekanik seperti ditunjukkan pada Tabel 2.

Tabel 2. Sifat mekanik material Al 6063-T5.

\begin{tabular}{ccccc}
\hline Material & $\begin{array}{c}\text { Density } \\
\left(\mathbf{g} / \mathbf{c m}^{\mathbf{3}}\right)\end{array}$ & $\begin{array}{c}\text { Yield Strength } \\
(\mathbf{M P a})\end{array}$ & $\begin{array}{c}\text { Tensile Strength } \\
(\mathbf{M P a})\end{array}$ & $\begin{array}{c}\text { Young Modulus } \\
(\mathbf{G P a})\end{array}$ \\
\hline $\mathrm{Al} 6063-\mathrm{T} 5$ & 2.85 & 145 & 186 & 68.9 \\
\hline
\end{tabular}

\section{HASIL DAN PEMBAHASAN}

Gambar 3 menunjukkan hasil simulasi tegangan von Mises tabung roket Dextrose untuk tekanan internal $1 \mathrm{MPa}$ dengan ketebalan dinding $2 \mathrm{~mm}$ (kiri) dan $2.5 \mathrm{~mm}$ (kanan). Hasil analisis tegangan statik menunjukkan bahwa tegangan von Mises maksimum menurun saat ketebalan dinding meningkat (Grafik 1). Tegangan von Mises maksimum terjadi pada bagian cap, baik ujung maupun pangkal silinder yang merupakan daerah kritis [11].

Gambar 4 menunjukkan hasil simulasi tegangan von Mises untuk ketebalan dinding $3 \mathrm{~mm}$ dengan tekanan internal $4 \mathrm{MPa}$ (kiri) dan $5 \mathrm{MPa}$ (kanan). Hasil analisis tegangan statik menunjukkan bahwa tegangan von Mises maksimum meningkat seiring peningkatan tekanan internal (Grafik 1).

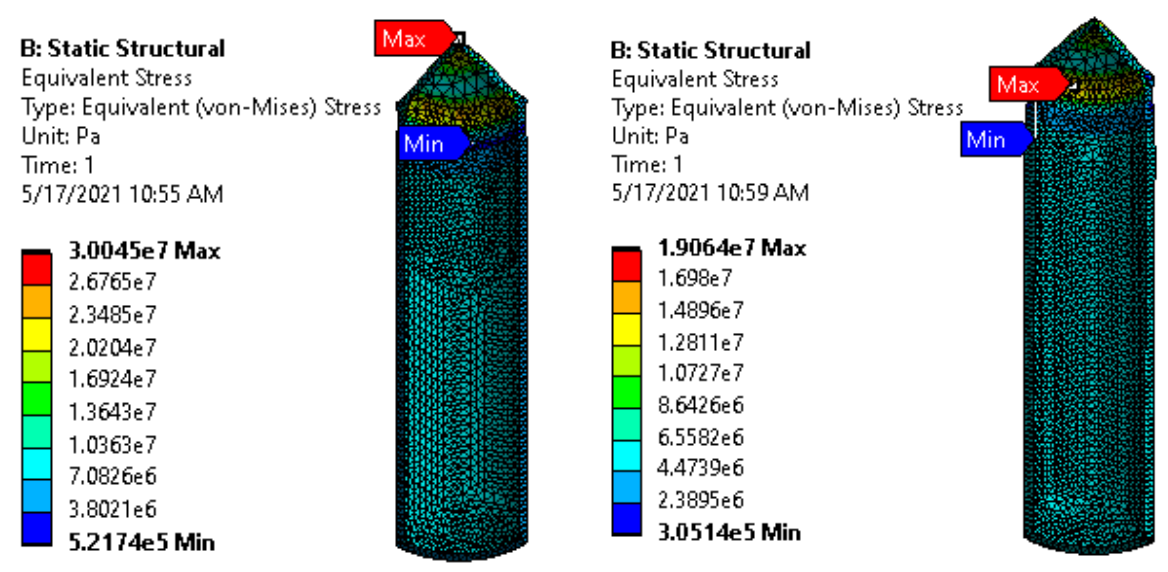

Gambar 3. Hasil simulasi tegangan von Mises untuk tekanan internal $1 \mathrm{MPa}$ dengan ketebalan dinding $2 \mathrm{~mm}$ (kiri) dan $2.5 \mathrm{~mm}$ (kanan) 

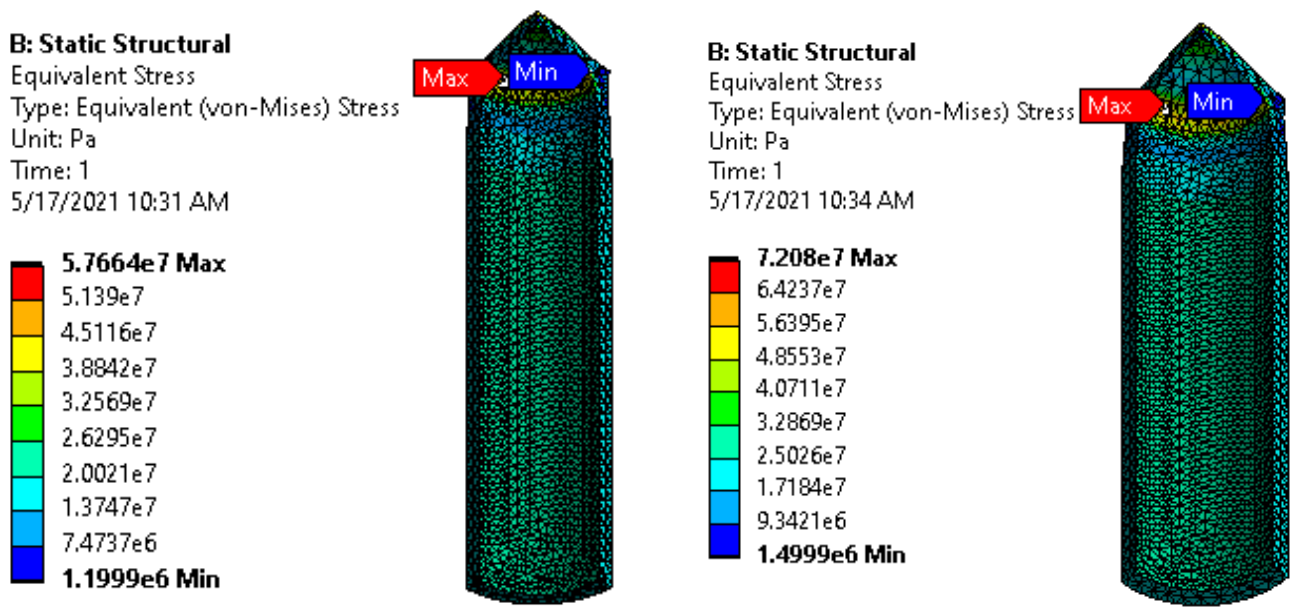

Gambar 4. Hasil simulasi tegangan von Mises untuk ketebalan dinding $3 \mathrm{~mm}$ dengan tekanan internal $4 \mathrm{MPa}$ (kiri) dan $5 \mathrm{MPa}$ (kanan)

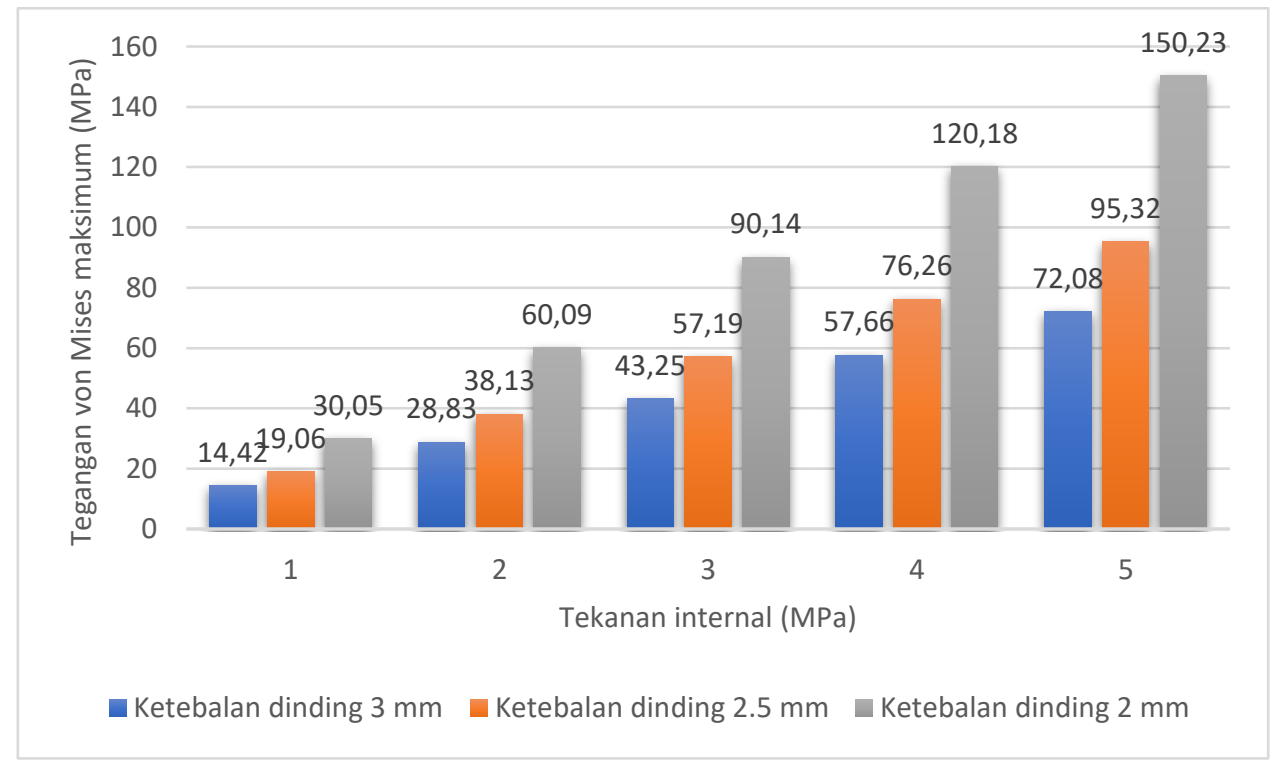

Grafik 1. Pengaruh tekanan internal dan ketebalan dinding terhadap tegangan von Mises maksimum tabung roket Dextrose.

Faktor keamanan digunakan sebagai salah satu faktor yang menjadi pertimbangan keamanan suatu komponen. Nilai faktor keamanan harus disesuaikan dengan kebutuhan suatu sistem. Faktor keamanan yang terlalu tinggi dapat menyebabkan semakin boros kebutuhan material yang digunakan. Faktor keamanan yang terlalu rendah menunjukkan semakin rentannya suatu sistem terhadap kegagalan. Faktor keamanan dihitung dari rasio antara kekuatan material dengan tegangan maksimum pada komponen tersebut. Kekuatan material dapat menggunakan salah satu dari batas tegangan luluh atau tegangan tarik maksimum dari material. Pada umumnya, komponen yang 
digunakan berulang-ulang menggunakan batas kekuatan luluh, sedangkan komponen yang digunakan sekali pakai menggunakan batas kekuatan maksimum. Pada penelitian ini, tabung roket Dextrose merupakan komponen habis pakai [10].

Grafik 2 menunjukkan pengaruh ketebalan dinding dan tekanan internal terhadap faktor keamanan minimum tabung roket Dextrose. Hasil analisis tegangan statik menunjukkan bahwa faktor keamanan akan meningkat seiring dengan peningkatan ketebalan dinding silinder. Kondisi ini berkebalikan dengan peningkatan tekanan internal. Faktor keamanan semakin menurun seiring dengan peningkatan tekanan internal.

Hasil simulasi tegangan statik untuk ketebalan dinding $2 \mathrm{~mm}$ dengan tekanan internal $4 \mathrm{MPa}$ dan $5 \mathrm{MPa}$, material memiliki faktor keamanan kurang dari 2.00. Hal ini membuktikan pada variasi ini material gagal menahan beban dinamik karena nilai faktor keamanan yang dipersyaratkan untuk beban dinamik adalah 2.00-3.00 [16]. Demikian juga ketika ketebalan dinding $2.5 \mathrm{~mm}$ dengan tekanan internal $5 \mathrm{MPa}$ material hanya memiliki faktor keamanan 1.95. Hal ini juga membuktikan bahwa tabung roket dengan ketebalan dinding $2.5 \mathrm{~mm}$ juga tidak mampu menahan beban dinamik pada tekanan internal $5 \mathrm{MPa}$. Tabung motor roket Dextrose dengan ketebalan $3 \mathrm{~mm}$ mampu menahan beban dinamik hingga 5 MPa karena memiliki faktor keamanan lebih dari 2, tepatnya 2.58 .

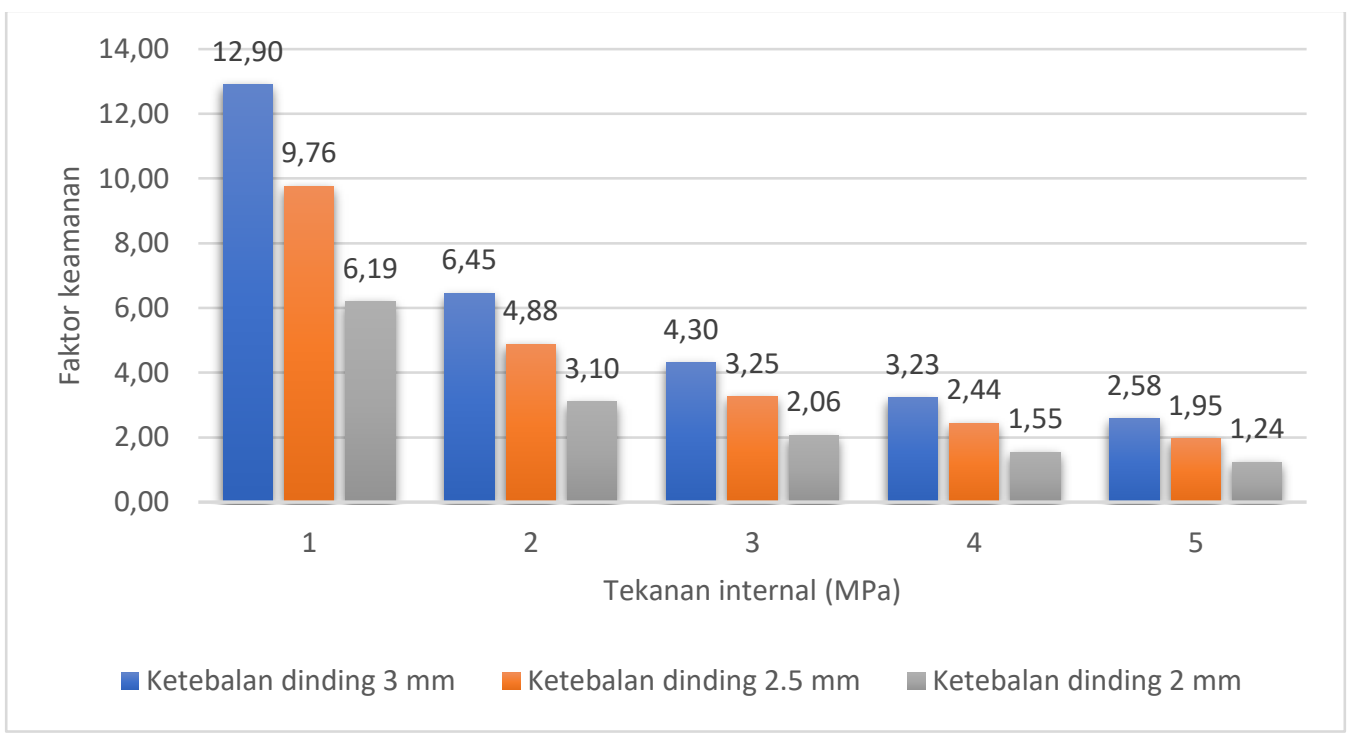

Grafik 2. Pengaruh ketebalan dinding dan tekanan internal terhadap faktor keamanan minimum tabung roket Dextrose.

Proses validasi hasil penelitian dilakukan dengan cara membandingkan nilai tegangan Longitudinal (axial) dan Hoop (circumferential) maksimum antara perhitungan analitik dengan simulasi Ansys Workbench. Hasil simulasi semakin valid jika persentase kesalahan semakin kecil. Gambar 5 menunjukkan nilai tegangan Hoop (kiri) dan Longitudinal (kanan) maksimum untuk variasi ketebalan dinding $2 \mathrm{~mm}$ dan tekanan internal $1 \mathrm{MPa}$, yaitu 7.53 MPa dan 3.27 MPa. Hasil simulasi Ansys menunjukkan ketebalan dinding dan tekanan internal sangat berpengaruh terhadap tegangan Longitudinal dan Hoop maksimum (Tabel 3). Kedua nilai tegangan baik menggunakan perhitungan analitik maupun simulasi Ansys Workbench hampir sama. Hasil perbandingan antara perhitungan analitik dan simulasi Ansys Workbench memiliki persentase kesalahan kurang dari 0.5 persen. 


B: Static Structural
Hoop Stress
Type: Normal Stress $\propto$ Axis)
Unit: Pa
Global Coordinate System
Time: 1
5/17/2021 10:16 AM
\begin{tabular}{|l}
$3.006 \mathrm{e} 7$ Max \\
$2.4109 \mathrm{e} 7$ \\
$1.8159 \mathrm{e} 7$ \\
$1.2209 \mathrm{e} 7$ \\
$6.2584 \mathrm{e} 6$ \\
$3.0807 \mathrm{e} 5$ \\
$-5.6422 \mathrm{e} 6$ \\
$-1.1593 \mathrm{e} 7$ \\
$-1.7543 \mathrm{e} 7$ \\
$-2.3493 \mathrm{e} 7$ Min
\end{tabular}

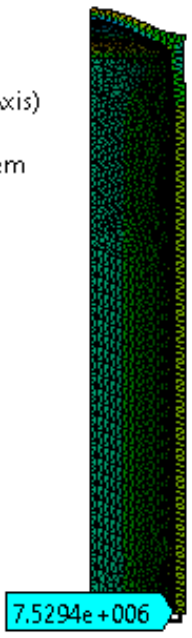

B: Static Structural Longitudinal Stress Type: Normal Stress( ( Axis) Unit: $\mathrm{Pa}$

Global Coordinate System Time: 1 $5 / 17 / 202110: 14 \mathrm{AM}$

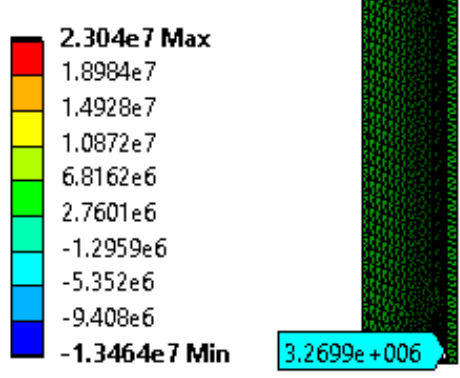

Gambar 5. Nilai tegangan Hoop (kiri) dan Longitudinal (kanan) maksimum untuk ketebalan dinding $2 \mathrm{~mm}$ dan tekanan internal $1 \mathrm{MPa}$.

Tabel 3. Persentase kesalahan antara perhitungan analitik dengan simulasi Ansys Workbench untuk nilai tegangan Hoop dan Longitudinal maksimum.

\begin{tabular}{|c|c|c|c|c|c|c|c|}
\hline \multirow{2}{*}{$\begin{array}{c}\text { Ketebalan } \\
\text { Dinding } \\
(\mathrm{mm})\end{array}$} & \multirow{2}{*}{$\begin{array}{c}\text { Tekanan } \\
\text { Internal } \\
(\mathrm{MPa})\end{array}$} & \multicolumn{2}{|c|}{ Perhitungan Analitik } & \multicolumn{2}{|c|}{$\begin{array}{l}\text { Simulasi Ansys } \\
\text { Workbench }\end{array}$} & \multicolumn{2}{|c|}{ Persentase Kesalahan } \\
\hline & & $\begin{array}{l}\text { Hoop } \\
\text { (MPa) }\end{array}$ & $\begin{array}{l}\text { Longitudinal } \\
\text { (MPa) }\end{array}$ & $\begin{array}{l}\text { Hoop } \\
\text { (MPa) }\end{array}$ & $\begin{array}{l}\text { Longitudinal } \\
\text { (MPa) }\end{array}$ & $\begin{array}{c}\text { Hoop } \\
(\%)\end{array}$ & $\begin{array}{c}\text { Longitudinal } \\
(\%)\end{array}$ \\
\hline 2 & 1 & 7.53 & 3.27 & 7.53 & 3.27 & 0.00 & 0.00 \\
\hline 2 & 2 & 15.07 & 6.53 & 15.07 & 6.53 & 0.00 & 0.00 \\
\hline 2 & 3 & 22.60 & 9.80 & 22.60 & 9.80 & 0.00 & 0.00 \\
\hline 2 & 4 & 30.13 & 13.07 & 30.13 & 13.06 & 0.00 & 0.08 \\
\hline 2 & 5 & 37.67 & 16.33 & 37.67 & 16.33 & 0.00 & 0.00 \\
\hline 2.5 & 1 & 5.94 & 2.47 & 5.94 & 2.47 & 0.00 & 0.00 \\
\hline 2.5 & 2 & 11.88 & 4.94 & 11.89 & 4.94 & 0.08 & 0.00 \\
\hline 2.5 & 3 & 17.83 & 7.41 & 17.83 & 7.41 & 0.00 & 0.00 \\
\hline 2.5 & 4 & 23.77 & 9.88 & 23.76 & 9.87 & 0.04 & 0.10 \\
\hline 2.5 & 5 & 29.71 & 12.36 & 29.73 & 12.35 & 0.07 & 0.08 \\
\hline 3 & 1 & 4.89 & 1.94 & 4.88 & 1.94 & 0.20 & 0.00 \\
\hline 3 & 2 & 9.77 & 3.89 & 9.76 & 3.88 & 0.10 & 0.26 \\
\hline 3 & 3 & 14.66 & 5.83 & 14.65 & 5.82 & 0.07 & 0.17 \\
\hline 3 & 4 & 19.54 & 7.77 & 19.53 & 7.76 & 0.05 & 0.13 \\
\hline 3 & 5 & 24.43 & 9.71 & 24.42 & 9.70 & 0.04 & 0.10 \\
\hline
\end{tabular}

Tegangan Hoop bersifat tarik (tensile). Tegangan Hoop maksimum dapat terjadi pada jari-jari luar atau jari-jari dalam tergantung pada arah gradien tekanan baik berupa tekanan internal maupun tekanan eksternal [17]. Jika hanya tekanan eksternal yang bekerja pada silinder berdinding tebal, maka tegangan Hoop maksimum terjadi pada jari-jari luar $\left(r=r_{0}\right)$. Pada penelitian ini, tegangan Hoop maksimum terjadi pada jari-jari dalam $\left(r=r_{i}\right)$ karena hanya mengalami tekanan internal. 
Pada silinder tertutup, tegangan di sepanjang arah sumbu silinder dipengaruhi oleh tekanan internal yang bekerja. Tegangan di sepanjang arah sumbu silinder ini disebut juga tegangan Longitudinal yang nilainya selalu lebih kecil dari tegangan Hoop.

\section{KESIMPULAN DAN SARAN}

Hasil simulasi tegangan statik menunjukkan tabung motor roket Dextrose dengan ketebalan $3 \mathrm{~mm}$ mampu menahan tekanan internal hingga $5 \mathrm{MPa}$ karena memiliki faktor keamanan lebih dari 2, yaitu 2.58.

Perbandingan nilai tegangan Longitudinal dan Hoop maksimum antara perhitungan analitik dan simulasi Ansys Workbench digunakan untuk validasi hasil penelitian. Hasil perbandingan antara perhitungan analitik dan simulasi Ansys Workbench memiliki persentase kesalahan kurang dari 0.5 persen.

Tegangan von Mises maksimum terjadi pada bagian cap, baik ujung maupun pangkal silinder yang menunjukkan daerah kritis. Pada penelitian berikutnya, faktor keamanan dapat ditingkatkan hanya dengan meningkatkan ketebalan cap pada ujung dan pangkal silinder tanpa meningkatkan ketebalan dinding pada selimut silinder. Hal ini sangat menguntungkan karena akan menurunkan berat tabung secara keseluruhan.

\section{DAFTAR PUSTAKA}

[1] B. Huseyin, S. Çoban, and A. Yapıc1, "Designing, Modeling and Simulation of Solid Fuel Rocket ALP-01,” Eur. J. Sci. Technol., no. 15, pp. 511-518, 2019.

[2] D. A. Singh, "Sugar Based Rocket Propulsion System- Making, Analysis \& Limitations," Int. J. Eng. Trends Appl., vol. 2, no. 5, pp. 30-37, 2013.

[3] B. Aliyu, C. Osheku, E. Oyedeji, M. Adetoro, A. Okon, and C. Idoko, "Validating a Novel Theoretical Expression for Burn time and Average Thrust in Solid Rocket Motor Design," Adv. Res., vol. 5, no. 4, pp. 1-11, 2015.

[4] G. O. Adeniyi, I. Nkere, L. M. Adetoro, and O. S. Sholiyi, "Performance Analysis of a DualFuel Sugar Based Solid Rocket Propellant," Eur. J. Eng. Technol. Res., vol. 6, no. 2, pp. 3441, 2021.

[5] C. Américo, D. F. Moro, C. H. Marchi, and F. Aguiar, "Development of a Ballistic Evaluation Motor for Knsu Burn Rate Measurements," in 18th Brazilian Congress of Thermal Sciences and Engineering, 2020, vol. 2020.

[6] R. R. Salazar et al., "Design, construction and experimental static testing of a solid rocket motor," Rev. UIS Ing., vol. 20, no. 2, pp. 97-108, 2021.

[7] L. A. N. Wibawa, K. Diharjo, W. W. Raharjo, and B. H. Jihad, "Stress Analysis of ThickWalled Cylinder for Rocket Motor Case under Internal Pressure," J. Adv. Res. Fluid Mech. Therm. Sci., vol. 70, no. 2, pp. 106-115, 2020.

[8] L. A. N. Wibawa, "Numerical Study of The Effect of Wall Thickness and Internal Pressure on Von Mises Stress and Safety Factor of Thin-Walled Cylinder for Rocket Motor Case," JST (Jurnal Sains dan Teknol., vol. 9, no. 1, pp. 30-38, 2020.

[9] L. A. N. Wibawa, K. Diharjo, W. W. Raharjo, and B. H. Jihad, "Effect of Cap Thickness and Internal Pressure on Von Mises Stress of Thick-Walled Cylinders for Rocket Motor Case," Teknik, vol. 41, no. 2, pp. 111-118, 2020.

[10] L. A. N. Wibawa, "Studi Numerik Pengaruh Radius Fillet dan Ketebalan Cap terhadap Tegangan Von Mises dan Faktor Keamanan Silinder Berdinding Tipis untuk Tabung Motor Roket," J. Rekayasa Mesin, vol. 15, no. 1, pp. 1-9, 2020.

[11] L. A. N. Wibawa, K. Diharjo, W. Raharjo, and B. H. Jihad, "The Effect of Fillet Radius and Length of The Thick-Walled Cylinder on Von Mises Stress and Safety Factor for Rocket Motor Case," AIP Conf. Proc., vol. 2296, no. 1, 2020.

[12] R. S. Khurmi and J. K. Gupta, A textbook of machine design, 14th ed., no. I. New Delhi: Eurasia Publishing House, 2005.

[13] Q. S. Masikh, M. Tariq, and P. K. Sinha, "Analysis of A Thin and Thick Walled Pressure 
Vessel for Different Materials," Int. J. Mech. Eng. Technol., vol. 5, no. 10, pp. 9-19, 2014.

[14] F. Dadkhah and J. Zecher, ANSYS Workbench Software Tutorial with Multimedia CD Release 11. Schroff Development Corporation, 2008.

[15] K. L. Lawrence, Ansys Workbench Tutorial Release 14. Schroff Development Corporation, 2012.

[16] V. Dobrovolsky and K. Zablonsky, Machine elements : a textbook. Moscow: Peace Publisher, 1978.

[17] L. Skinner, "Snubbing Theory and Calculations," in Hydraulic Rig Technology and Operations, Gulf Professional Publishing, 2018, pp. 189-275. 